\title{
Preparation, Characterization and Photocatalytic Behaviour of Codoped Nanophotocatalyst
}

\author{
E. K. KIRUPAVASAM* and G. ALLEN GNANA RAJ \\ Department of Chemistry and Research Centre, Scott Christian College, (Autonomous) \\ Nagercoil, Tamilnadu, India \\ kirupavasam@yahoo.co.in
}

Received 22 January 2013 / Accepted 16 February 2013

\begin{abstract}
TiO}_{2}$ has gained great popularity for environmental treatment and purification process; however it shows poor absorption of visible light and requires UV light for activation. CNS codoped $\mathrm{TiO}_{2}\left(\mathrm{CNS}-\mathrm{TiO}_{2}\right)$ photocatalyst prepared by sol-gel method is visible light active. The photocatalyst was characterized by $\mathrm{x}$-ray diffraction, scanning electron microscopy with EDAX analysis. Amidoblack-10B dye (AB-10B) solution under visible light irradiation was used to determine the photocatalytic activity. The photocatalytic test indicated that the modified $\mathrm{TiO}_{2}$ photocatalyst has higher visible light activity than $\mathrm{TiO}_{2}$.
\end{abstract}

Keywords: Photocatalyst, Co-doping, $\mathrm{TiO}_{2}$, Visible-light active

\section{Introduction}

Textile wastewaters contain usually a considerable amount of unfixed dyes, many of which are azo dyes ${ }^{1}$. It is estimated that $15 \%$ of the total world dye production is lost during dyeing process and it is released in textile effluents. The colours produced by minute amount of dye accidentally released in water during dyeing process are considered to pose serious problems because they have considerable environmental effects on the water and make them visually unpleasant ${ }^{2}$. Azo dyes are known to be largely nonbiodegradable. In order to overcome this problem, azo dyes can be degraded under anaerobic conditions, but in this case potentially hazardous and carcinogenic aromatic amines are produced ${ }^{3}$. It is a well-known fact that azo dyes structure when incorporated into the body is split by liver enzymes and intestinal flora into the corresponding aromatic amines, which can cause cancer in humans.

One of the drawbacks of $\mathrm{TiO}_{2}$ for photocatalytic process is its relative big band gap $3.0 \mathrm{eV}$ for rutile phase and $3.2 \mathrm{eV}$ for anatase phase respectively. As a result, $\mathrm{TiO}_{2}$ absorbs light wavelength less than $388 \mathrm{~nm}$ and the photocatalytic processes only occur in this region. Therefore many studies have employed in the modifications of $\mathrm{TiO}_{2}$ in order to improve its catalytic efficiency through enhancement of its absorbance in the visible light region to match the solar spectrum. Those methods consist of doping with metals ${ }^{4}$, non-metals ${ }^{5}$ and dye sensitization 6 . 
The general strategies have been developed to increase the photocatalytic activity of $\mathrm{TiO}_{2}$ for visible light irradiation, namely the use of an organic dye as photosensitiser or doping $\mathrm{TiO}_{2}$ with metallic and non-metallic elements. This doping promotes titania in the visible region and introduces occupied or unoccupied orbitals in the band gap region leading to negative or positive doping ${ }^{7}$. Doped ions can act as charge trapping sites and thus reduce electron-hole recombination. Noble metals doped or deposited on $\mathrm{TiO}_{2}$ are expected to show various effects on the photocatalytic activity of $\mathrm{TiO}_{2}$ by different mechanisms. They modify the surface properties of photocatalysts ${ }^{8}$. Introduction of dopants allows titania to absorb in the visible region but this does not necessarily mean that the doped catalyst has a better photocatalytic activity. When the doping level exceeds an optimal limit, which usually lies at very low dopant concentration and low visible light absorption, the dopant causes recombination of sites and has undesirable effects on photocatalysis ${ }^{9}$.

Co-doping of $\mathrm{TiO}_{2}$ may be used as an effective way to improve charge separation. Xu et al. ${ }^{10}$ synthesised $\mathrm{Ce}$, C-codoped $\mathrm{TiO}_{2}$ using a modified sol-gel method under mild conditions. The photocatalytic activity of $\mathrm{Ce}, \mathrm{C}$-codoped $\mathrm{TiO}_{2}$ for degradation of Reactive Brilliant Red $\mathrm{X}-3 \mathrm{~B}$ under visible light was significantly improved compared with that of C-doped $\mathrm{TiO}_{2}$, undoped $\mathrm{TiO}_{2}$ and Degussa $\mathrm{P} 25$ because cerium doping slowed the radiative recombination of photogenerated electrons and holes in $\mathrm{TiO}_{2}$. Shen et al. ${ }^{11}$ prepared an $\mathrm{N}$, Ce-co-doped $\mathrm{TiO}_{2}$ photocatalyst by the sol-gel route that could degrade nitrobenzene under irradiation with visible light. Nitrogen atoms were incorporated into the $\mathrm{TiO}_{2}$ crystal structure to narrow the band gap energy. The dopant cerium atoms existed in the form of $\mathrm{Ce}_{2} \mathrm{O}_{3}$ and were dispersed on the surface of $\mathrm{TiO}_{2}$. The improvement in the photocatalytic activity was ascribed to the synergistic effects of nitrogen and cerium co-doping.

\section{Experimental}

Titanium tetra isopropoxide was used as the precursor in the synthesis of nano $\mathrm{TiO}_{2}$ and was purchased from Aldrich with $97 \%$ purity. For all the experiments double distilled water was used. The organic solvents used were purchased from Merck (Germany). The textile dye (AB-10B) was pcurchased from S.D fine chemicals India Ltd.

\section{Preparation of carbon, nitrogen, sulphur doped $\mathrm{TiO}_{2}$ photocatalyst (CNS Doped $\mathrm{TiO}_{2}$ )}

Carbon, nitrogen, sulphur doped $\mathrm{TiO}_{2}$ photocatalyst was prepared by a simple hydrolysis process using titanium isopropoxide as the precursor of titanium, and thiourea as the source for carbon, nitrogen and sulphur ${ }^{12} .10 \mathrm{~mL}$ of titanium isopropoxide solution was mixed with $30 \mathrm{~mL}$ of isopropyl alcohol solution. This solution was added drop wise to required amount of deionised water containing in a $250 \mathrm{~mL}$ beaker. The solution was thoroughly mixed using a magnetic stirrer for $4 \mathrm{~h}$. To this solution, required amount of thiourea, dissolved double distilled water was added. The weight percentage of thiourea doped $\mathrm{TiO}_{2}$ was 5 wt $\%$. The mixture was stirred for $6 \mathrm{~h}$ and dried in oven at $80{ }^{\circ} \mathrm{C}$ for $12 \mathrm{~h}$. The solid product formed was further calcined at $400{ }^{\circ} \mathrm{C}$ temperature for $6 \mathrm{~h}$ in air to get $\mathrm{C}, \mathrm{N}$, and $\mathrm{S}$ doped $\mathrm{TiO}_{2}$ photocatalyst.

\section{Characterisation of photocatalyst}

The x-ray powder diffraction (XRD) pattern was measured on an X-pert PRO (PAN alytical) diffractometer at room temperature with cuk $\alpha$ radiation. XRD diagrams were obtained for the range of $2 \theta=20-80^{\circ}$. The size of $\mathrm{TiO}_{2}$ nanocrystals was estimated by means of the Scherrer equation from broadening of the (101) anatase reflection. Scanning electron microscope (SEM) analysis was performed on platinum coated samples using a JEOL apparatus model JSM - 5610LV, equipped with an INCA EDX probe for the energy dispersive $\mathrm{X}$-ray micro analysis (EDAX). 


\section{Photocatalytic experiments}

The experiments were performed in a borosilicate glass of $250 \mathrm{~mL}$ capacity. A certain amount of AB- $\square$ 10B dye was dissolved in $100 \mathrm{~mL}$ of distilled water, resulting in a solution with $\mathrm{pH}$ 7. 6. Prior to irradiation, a suspension containing definite amount of catalyst and $100 \mathrm{~mL}$ of $\mathrm{AB}-10 \mathrm{~B}$ dye solution was stirred continuously in the dark for $30 \mathrm{~min}$ to achieve the adsorption equilibrium of dye on the surface of the catalyst. The concentration of substrate in bulk solution at this point was used as the initial value for the further kinetic treatment of the photodegradation process. The solution was irradiated using solar light. At given intervals of irradiation, a sample of the solution along with catalyst particles was collected, centrifuged and then filtered through a millipore filter (pore size $0.22 \mathrm{~m}$ ). The filtrates were analyzed by UV-visible spectrophotometer. The determination wavelength is $620 \mathrm{~nm}$ for $\mathrm{AB}-10 \mathrm{~B}$, which is the maximum absorption wavelength.

\section{Results and Discussion}

\section{Surface characteristics of the sample}

The micro surface structures and morphology of CNS doped $\mathrm{TiO}_{2}$ were characterized by SEM. SEM is used for inspecting topographies of specimens at very high magnifications using a piece of equipment called scanning electron microscope. Figure 1 and Figure 2 shows the macroscopic changes in the morphology of $\mathrm{TiO}_{2}$ and $\mathrm{CNS}-\mathrm{TiO}_{2}$.

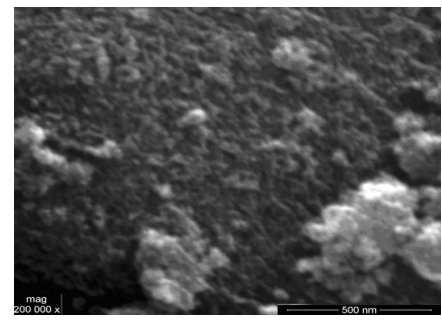

Figure 1. SEM of undoped $\mathrm{TiO}_{2}$

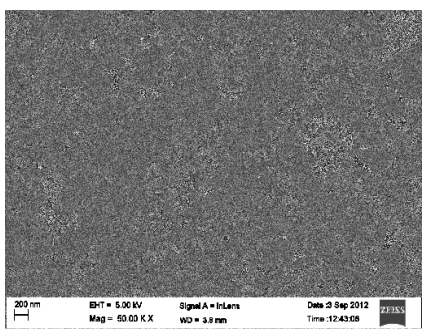

(a)

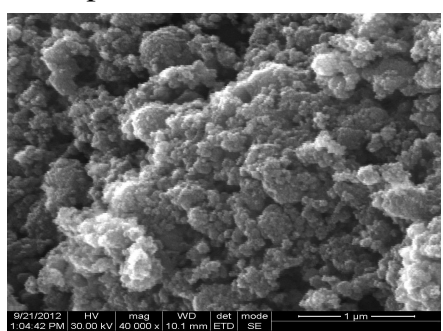

(b)

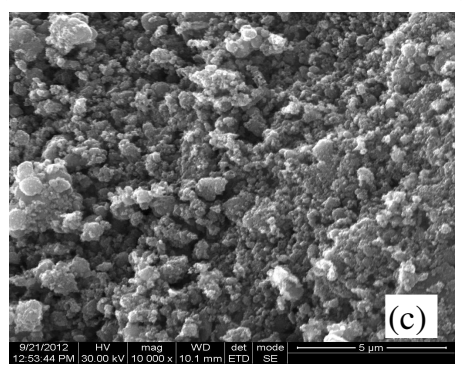

Figure 2. SEM of CNS doped $\mathrm{TiO}_{2}$ (a) SEM at 200nm; (b) at $1 \mu \mathrm{m}$ and (c) at $5 \mu \mathrm{m}$ 
In Figure 2, CNS-doped $\mathrm{TiO}_{2}$ has the small particle size and a good dispersion. The doped $\mathrm{CNS}-\mathrm{TiO}_{2}$ was spherical particles in shape with small facets. Zhang et al. reported that a good dispersion of small particles could provide more reactive sites for the reactants than the aggregated particles ${ }^{13}$.

\section{Structural analysis}

XRD was used to determine the crystallographic structure of the inorganic component of the photocatalyst. Figure 3 shows the XRD patterns of $\mathrm{CNS}-\mathrm{TiO}_{2}$. It can be seen that $\mathrm{CNS}-\mathrm{TiO}_{2}$ exhibits only the characteristic peak of anatase (major peaks at $25.41^{\circ}, 38^{0}, 48^{0}, 55^{\circ}$ ) and no rutile phase is observed. The results are in good agreement with earlier studies ${ }^{14}$. By applying Debye Scherrer equation, the average particle size of the $\mathrm{CNS}^{-\mathrm{TiO}_{2}}$ catalysts is found to be $15 \mathrm{~nm}$. It can be inferred that the ratio of thiourea to titania slightly influences the crystallisation of the mesoporous titania.

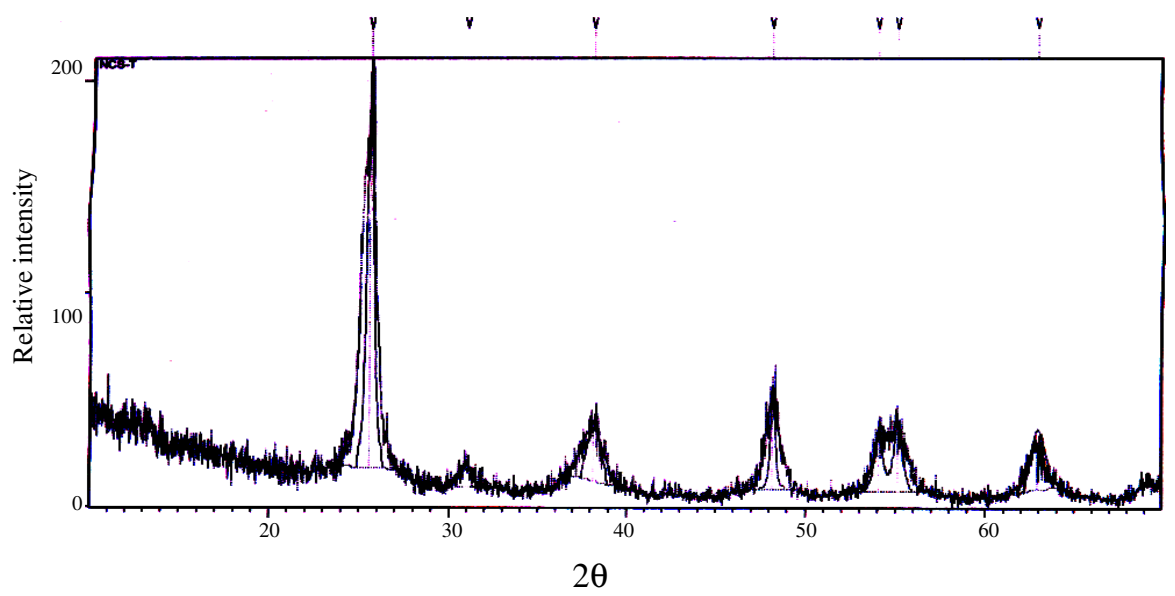

Figure 3. XRD patterns of $\mathrm{CNS}-\mathrm{TiO}_{2}$

\section{Elemental analysis of the sample}

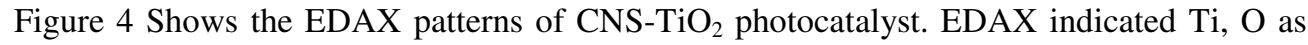
the major elements in the photocatalyst. Figure 4 confirms the presence of dopant $\mathrm{C}, \mathrm{N}, \mathrm{S}$ which are indicated by the strong peaks.

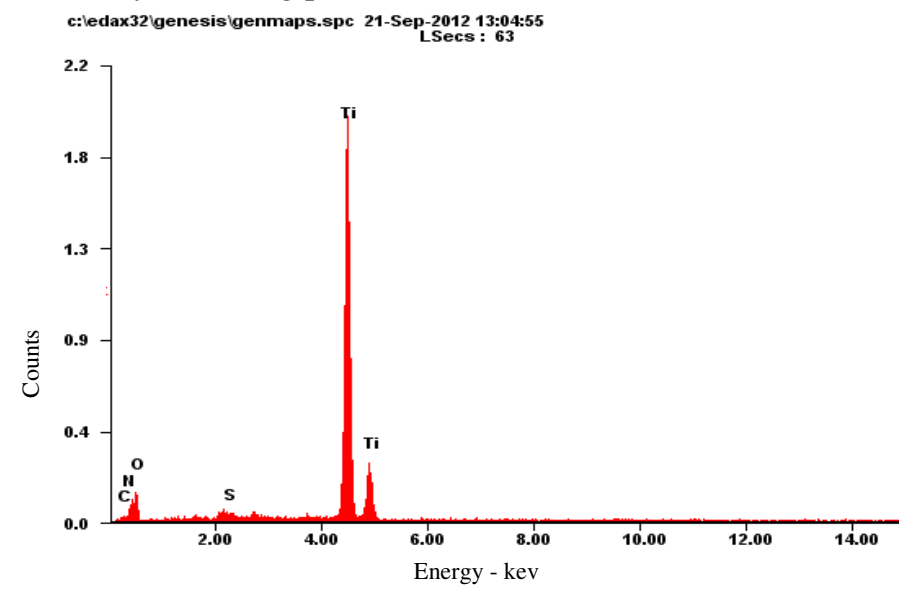




\begin{tabular}{cll}
\hline Element & \multicolumn{1}{c}{$\mathrm{wt} \%$} & $\mathrm{At} \%$ \\
\hline CK & 04.56 & 09.01 \\
NK & 08.84 & 14.99 \\
OK & 33.28 & 49.42 \\
SK & 00.50 & 00.37 \\
TiK & 52.82 & 26.20 \\
Matrix & Correction & ZAF
\end{tabular}

Figure 4. EDAX analysis of $\mathrm{CNS}-\mathrm{TiO}_{2}$

\section{Photocatalytic activity of the photocatalyst}

$0.05 \mathrm{~g}$ of Photocatalyst was suspended in $100 \mathrm{~mL}$ aqueous $\mathrm{AB}-10 \mathrm{~B}$ dye solution (20 ppm) in a water jacketed reactor and its temperature was kept at $25{ }^{\circ} \mathrm{C}$. The suspension was kept in the dark to establish adsorption-desorption equilibrium. Then the suspension was irradiated under visible light. Samples were withdrawn periodically, centrifuged and analyzed for the degradation of $\mathrm{AB}-10 \mathrm{~B}$ using a UV-visible spectrophotometer. AB-10B has the maximum absorbance at $620 \mathrm{~nm}$ and that was taken as a way for following up the dye degradation. Figure 5 and 6 shows the UV-visible spectra of AB-10B dye and the dye degraded in the presence of photocatalyst.

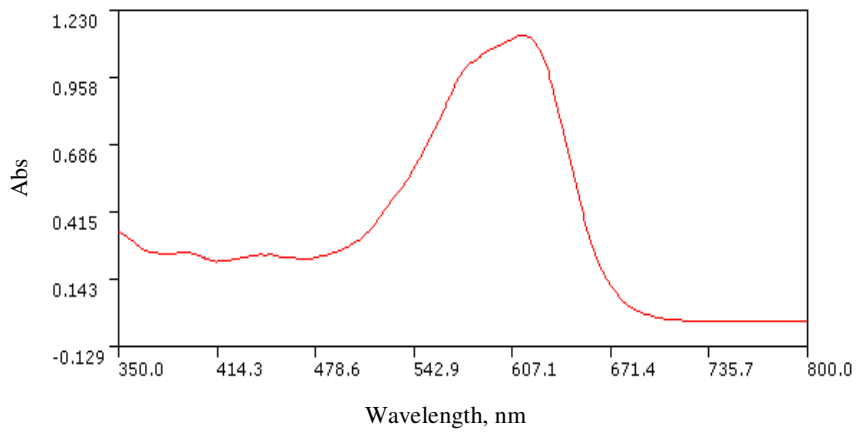

Figure 5. UV-visible spectra of the dye AB-10B

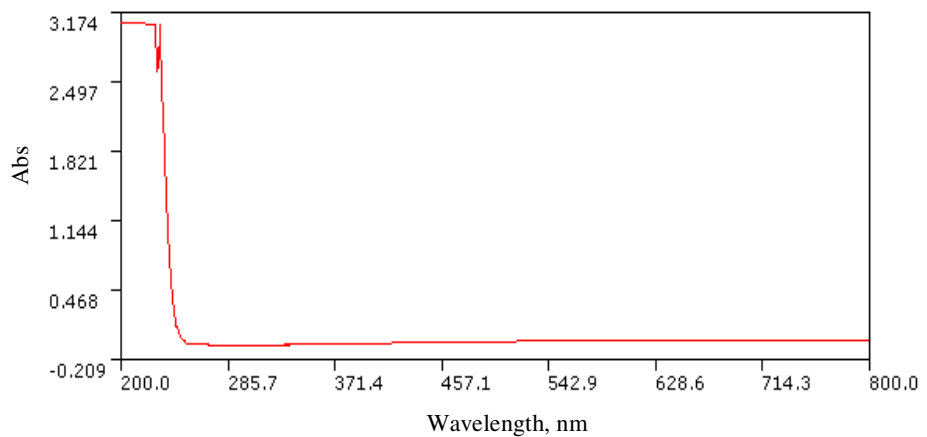

Figure 6. UV-visible spectra for the degradation of $\mathrm{AB}-10 \mathrm{~B}$ dye using $\mathrm{CNS}-\mathrm{TiO}_{2}$

\section{Conclusion}

This study examined the preparation and characterization of $\mathrm{CNS}-\mathrm{TiO}_{2}$ photocatalyst. The co-doped $\mathrm{TiO}_{2}$ showed higher activity than pure $\mathrm{TiO}_{2}$ for the degradation of $\mathrm{AB}-10 \mathrm{~B}$ dye under visible light irradiation. The high activity was related to the several beneficial effects associated with the introduction of nitrogen, carbon and sulphur. 


\section{References}

1. Chen C, Wang Z, Ruan S, Zou B, Fengqing Wu and Zhao M, Dyes Pigm., 2008, 77(1), 204-209.

2. Wang C-C, Lee C-K, Lyu M, Lain-Chuen Juang and Juang L-D, Dyes Pigm., 2008, 76(3), 817-824.

3. Bizani E, Fytianos K, Poulios I and Tsiridis V, J Hazard Mater., 2006, 136(1), 85-94.

4. Sakata Y, Yamamoto T, Tsuchiya S, Okazaki T and Imamura H, Chem Lett., 1998, 12, 1253-1254.

5. Mrowetz M, Balcerski W, Colussi A J and Hoffman M R, J Phys Chem B, 2004, 108, 17269-17273.

6. Cho Y M, Choi W Y, Lee C H, Hyeon T and Ho-In Lee, Environ Sci Technol., 2001, 35(5), 966-970.

7. Gaya U I and Abdullah A H, J Photochem Photobiol C: Photochem Rev., 2008, 9(1), 1-12.

8. Liu Y, Liu C-Y, Rong Q, Qing-hui Rong and Zhang Z, Appl Surf Sci., 2003, 220(1-4), 7-11.

9. Bouras P, Stathatos E and Lianos P, Appl Catal B: Environ., 2007, 73, 51-59.

10. Xu J, Ao Y and Fu D, Appl Surf Sci., 2009, 256(3), 884-888.

11. Shen X Z, Liu Z C, Xie S M and Guo J, J Hazard Mater., 2009, 162(3), 1193-1198.

12. Gandhe A R and Fernandes J B, Bulletin Catalysis Society of India, 2005, 4(4), 131-134.

13. Zhang X, Zhou M and Lei L, Carbon, 2005, 43(8), 1700-1708. 